\title{
PERAN PENYULUHAN TERHADAP PEMANFAATAN LIMBAH PERUSAHAAN PETERNAKAN AYAM RAS DI DESA TATELI KECAMATAN MANDOLANG KABUPATEN MINAHASA
}

\author{
Asral Gobel, Adrie A. Sajow, Stanly.O.B. Lombogia*, Gam.D. Lenzun
}

\section{Fakultas Peternakan Universitas Sam Ratulangi Manado, 95115}

\begin{abstract}
ABSTRAK
Penelitian ini bertujuan untuk (1) mengetahui persepsi peternak terhadap peran penyuluhan dalam pemanfaatan limbah perusahaan peternakan, (2) mengetahui tingkat pengetahuan peternak terhadap pemanfaatan limbah perusahaan peternakan. Jenis Penelitian ini menggunakan dekriptif kualitatif yaitu untuk mengungkapkan kejadian atau fakta, keadaan, fenomena variabel dan keadaan yang terjadi saat penelitian berlangsung. Pemilihan populasi dan sampel ditentukan secara sengaja (purposive) yaitu dengan 3 perusahaan peternakan yang ada di Desa Tateli kemudian dalam setiap perusahaan ditentukan 10 orang sehingga jumlah 30 orang untuk dijadikan responden. Hasil penelitian menunjukan bahwa peran penyuluhan dalam pemanfaatan limbah perusahaan peternakan di Desa Tateli Kecamatan Mandolang Kabupaten Minahasa yang dilihat dari variabel edukasi dengan skor 4,09 menunjukan kategori baik, diseminasi skore 3,94 menunjukan baik, fasilitasi 4,23 menunjukan sangat baik, konsultasi 4,03 menunjukan baik, supervisi 4,23 sangat baik dan monitoring/evaluasi 4,12 dimana sudah dalam kategori baik. Sehingga untuk persepsi peternak terhadap peran penyuluhan sudah dalam ketagori baik yang di tunjukan dengan skor 4,10. Sedangkan untuk persepsi pemanfaatan limbah perusahaan peternakan menunjukan sangat baik dengan skor 4,26. Berdasarkan persepsi peternak terhadap pemanfaatan limbah perusahaan
\end{abstract}

*Korespondensi (corresponding author) Email:lombogiastanly@yahoo.co.id peternakan, peran penyuluhan dalam kategori baik, hal ini diperlihatkan peternak dengan menerapkan pengetahuan dan keterampilan dalam pemanfaatan limbah ternak untuk dijadikan pupuk dan pakan ikan sehinggah menyebabkan peningkatan ekonomi serta menanggulangi dampak lingkungan.

Kata Kunci : Peran Penyuluhan, Pemanfaatan Limbah

\section{ABSTRACT}

\begin{tabular}{|c|c|c|}
\hline $\mathrm{HE}$ & & \\
\hline ELUCIADATION & $\mathbf{O N}$ & W \\
\hline UTILIZA & $\mathbf{O F}$ & - \\
\hline ING IN & TATELI & \\
\hline DOLANG & DISTI & CT \\
\hline
\end{tabular}
was done to (1) evaluate perception of farmer on role of counseling elucidation dealing with waste utilization of poultry farm, (2) to study knowledge level of farmer dealing with waste utilization of poultry farm. Study was conducted using descriptive qualitative method. Sample was taken on the basis of purposive sampling involving three poultry farms at Tateli village. Each poultry farm involved 10 personal workers as the respondents. Results showed that the role of counseling elucidation dealing with waste utilization of poultry farm at Tateli village based on variable of education score was 4.09 indicating good category, variable of dissemination score was 3.94 indicating very good category, variable of facilitation score was 4.23 indicating very good category, and variable of monitoring or evaluation score was 4.12 indicating good category. The perceptionof farmers on the role of counseling elucidation dealing with 
waste utilization of poultry farm at Tateli village was categorized into score of 4.10 indicating good category. The perception of farmers on waste utilization of poultry farm at Tateli village was categorized into score of 4.26 indicating very good category. Therefore, general role of counseling elucidation dealing with waste utilization of poultry farm at Tateli village was categorized into good classification showing by activity applying animal waste product as the organic fertilizer for plant and as the feedstuff ingredient in formulation of fish feeding for increasing income over feed cost and environmental conservation.

Key Word : counseling elucidation role, poultry waste utilization

\section{PENDAHULUAN}

\section{Latar Belakang}

Penyuluhan pada dasarnya adalah pendidikan dimana target yaitu para peternak harus mengalami perubahan perilaku, dari mulai aspek yang bersifat kognitif, afektif dan akhirnya psikomotorik(Adjid, 2001). Penyuluhan sebagai proses perubahan perilaku melalui pendidikan akan memakan waktu lebih lama, tetapi perubahan perilaku yang terjadi akan berlangsung lebih kekal. Sebaliknya, meskipun perubahan perilaku melalui pemaksaan dapat lebih cepat dan mudah dilakukan, tetapi perubahan perilaku tersebut akan segera hilang, manakala faktor pemaksanya sudah dihentikan,oleh karena itu penyuluhan merupakan investasi untuk masa depan (Amanah, 2007). Hasil dari penyuluhan tidak dapat diketahui dalam waktu yang singkat terlebih lagi jika tujuan utama suatu program penyuluhan adalah terjadinya adopsi suatu inovasi yang ditawarkan atau terjadinya perubahan perilaku sasaran tentu akanmembutuhkan waktu yang relatif lama.Usaha peternakan ayam akhir-akhir ini mulai sering dikatakansebagai usaha yang ikut mencemari lingkungan, oleh karena ituRisnaet al., (2012) mengemukakan agar peternakan ayam tersebut merupakan suatu usaha yang berwawasan lingkungan dan efisien, maka tatalaksana pemeliharaan, perkandangan dan penanganan limbahnya harus selalu diperhatikan.

\section{METODE PENELITIAN}

\section{Lokasi dan Waktu Penelitian}

Penelitian ini dilaksanakan selama dua bulan, yaitu pada bulan Mei-Juni 2017 dan bertempat di Desa Tateli Kecamatan Mandolang Kabupaten Minahasa.

\section{Penentuan Populasi dan Sampel}

1. Penentuan populasi ditentukan secara sengaja (purposive) yaitu seluruh perusahaan peternakan ayam ras di Desa Tateli Kecamatan Mandolang Kabupaten Minahasa.

2. Penentuan sampel dilakukan secara (Purposive Sampling) dengan pertimbangan bahwa lokasi yang kegiatan penyuluhannya aktif. 


\section{Teknik Pengumpulan Data}

1. Teknik Observasi yaitu teknik pengumpulan data yang dilakukan dengan mengadakan pengamatan langsung pada objek yang diteliti.

2. Kuesioner yaitu teknik pengumpulan data dengan menyebarkan daftar pertanyaan kepada responden.

3. Teknik wawancara yaitu pengumpulan data yang diperoleh dengan bertanya langsung kepada informan menggunakan daftar pertanyaan tertulis, data yang diperoleh dipergunakan sebagai data primer.

4. Teknik pencatatan yaitu mencatat data yang diperlukan dari instansi terkait yang berhubungan dengan penelitian, data yang diperoleh digunakan untuk data sekunder.

\section{Metode Analisis Data}

Data kualitatif diukur menurut Scale Likert,responden dianalisis untuk mengetahui item-item mana yang sangat nyata batasan antara skor tinggi dan skor rendah dalam skala total. Skor nilai jawaban yang diberikan responden untuk peran penyuluhan terhadap pemanfaatan limbah perusahaan peternakan.Berdasarkan Tabel 1 persepsi peran penyuluhan terhadap pemanfaatan limbah perusahaan peternakan skor nilai jawaban tertutup dari peternak dibuat dalam bentukpernyataan positif (jawaban yang diharapkan) diberi skor 5 hingga pernyataan negatif (jawaban yang tidak diharapkan) diberi skor 1 (Sugiyono, 2012). Tabel 2 menjelaskan skor nilai jawaban tertutup dari peternak dalam pemanfaatan limbah perusahaanpeternakan dibuat dalam bentuk pernyataan positif (jawaban yang diharapkan) diberi skor 5 hingga pernyataan negatif (jawaban yang tidak diharapkan) diberi skor 1 (Sugiyono, 2012).

Tabel 1. Skor Nilai Jawaban Yang Diberikan Responden Untuk Peran Penyuluhan.

\begin{tabular}{lc}
\hline Persetujuan Terhadap Pernyataan & Skor Nilai \\
\hline Sangat Baik(SB) & 5 \\
Baik (B) & 4 \\
Cukup Baik (C) & 3 \\
Tidak Baik (K) & 2 \\
Sangat TIdak Baik (SK) & 1 \\
\hline
\end{tabular}

Tabel 2.Skor Nilai Jawaban Yang Diberikan Responden Untuk Pemanfaatan Limbah.

\begin{tabular}{lc}
\hline Persetujuan Terhadap Pernyataan & Skor Nilai \\
\hline Sangat Baik (SB) & 5 \\
Baik (B) & 4 \\
Cukup Baik (C) & 3 \\
Tidak Baik (K) & 2 \\
Sangat Tidak Baik (SK) & 1 \\
\hline
\end{tabular}


Tabel 3. Kategori Skor UntukPersepsi Peran Penyuluhan.

\begin{tabular}{ll}
\hline \multicolumn{1}{c}{ Kategori } & Skor Persepsi Peran Penyuluhan \\
\hline Sangat Baik (SB) & Skor \\
Baik (B) & $4,20-5,00$ \\
Cukup Baik (C) & $3,40-4,19$ \\
Tidak Baik (K) & $2,60-3,39$ \\
Sangat Tidak Baik (SK) & $1,80-2,59$ \\
\hline
\end{tabular}

Tabel 4.Kategori Skor Persepsi Pemanfaatan Limbah

\begin{tabular}{lc}
\hline \multicolumn{1}{c}{ Skor Persepsi Pemanfaatan Limbah } \\
\hline Kategori & Skor \\
\hline Sangat Baik (SB) & $4,20-5,00$ \\
Baik (B) & $3,40-4,19$ \\
Cukup Baik (C) & $2,60-3,39$ \\
Tidak Baik (K) & $1,80-2,59$ \\
Sangat Tidak Baik (SK) & $1,00-1,79$ \\
\hline
\end{tabular}

Rumus: $T \boldsymbol{x} P \boldsymbol{P}$

$T=$ Total jumlah responden yang memilih

$P n=$ Pilihan angka skor Likert

\section{Rumus Rentan Skala}

$$
\begin{aligned}
& R S=\frac{\text { Skortinggih }- \text { Skor rendah }}{\text { Skortinggih }} \\
& -0,01 \\
& \mathrm{RS}=\frac{5-1}{5}-0,01 \\
& \mathrm{RS}=0,79
\end{aligned}
$$

Berdasarkan rumus rentan skala ditentukan batasan kategori skor persepsi peternak untuk peran penyuluhan terhadap pemanfaatan limbah perusahaan peternakan.Nilai skor masing-masing kategori pada setiap variabel, ditentukan kategori skor bagi masing-masing variabel peran penyuluhan peternakan berdasarkan kategori persepsi peternak terdapat pada Tabel 3. Berdasarkan nilai skor masing- masing kategori pada variabel, tingkatan kategori persepsi untuk mengetahui pesepsi peternak dalam pemanfaatan limbah perusahaan peternakan dapat diamati pada Tabel 4.

\section{HASIL DAN PEMBAHASAN}

\section{Penilaian Persepsi Peternak Terhadap}

\section{Peran Penyuluhan}

Hasil analisis dari persepsi peternak terhadap peran penyuluhan dalam pemanfaatan limbah perusahaan peternakan di Desa Tateli Kecamatan Mandolangmenunjukan peran penyuluhan dalam pemanfaatan limbah perusahaan peternakan yang diukur dari variabel edukasi, diseminasi, fasilitasi konsultasi supervisi dan monitoring/evaluasi (Mardikanto, 2009) dalam kategori baik yang ditunjukan dengan skor 4,10 seperti yang tersaji pada tabel 5 . 
Tabel 5. Penilaian Persepsi Peternak Terhadap Peran Penyuluhan

\begin{tabular}{lll}
\hline Variabel dan Indikator & Skor & Kategori \\
\hline Edukasi & 4,09 & Baik \\
1. Relevansi materi dengan kebutuhan & 4,20 & Sangat baik \\
2. Peningkatan pengetahuan & 4,06 & Baik \\
3. Peningkatan ketrampilan & 4,13 & Baik \\
4. Lama waktu kunjungan & 4,00 & Baik \\
\hline Diseminasi & 3,94 & Baik \\
1. Penyebaran informasi ke peternak lain & 3,86 & Baik \\
2. Informasi teknologi & 3,83 & Baik \\
3. Harga hasil limbah & 4,13 & Baik \\
\hline Fasilitasi & 4,23 & Sangat baik \\
1. Memfasilitasi keluhan peternak & 4,40 & Sangat baik \\
2. Pengembangan minat berusaha & 4,20 & Sangat baik \\
3. Kemitraan peternak dan pengusaha & 4,26 & Sangat baik \\
4. Akses ke lembaga keuangan & 4,13 & Baik \\
5. Penanganan akses pasar & 4,20 & Sangat baik \\
\hline Konsultasi & 4,03 & Baik \\
1. Pemecahan masalah & 3,96 & Baik \\
2. Sarana dan prasarana & 4,00 & Baik \\
3. Pemahaman teknologi & 4,13 & Baik \\
4. Waktu konsultasi secara rutin & 4,03 & Baik \\
\hline Supervisi & 4,23 & Sangat baik \\
1. Pembinaan kemampuan teknik & 4,43 & Sangat baik \\
2. Pembinaan pemasaran & 4,33 & Sangat baik \\
3. Pembinaan SDA dan SDM & 3,39 & Baik \\
\hline Evaluasi & 4,12 & Baik \\
1. Evaluasi terhadap usaha & 4,16 & Baik \\
2. Penguasaan inofasi teknologi baru & 4,33 & Sangat baik \\
3. Hasil kegiatan/output & 3,96 & Baik \\
4. Kinerja teknis dan finansial & 4,06 & Baik \\
\hline Peran penyuluhan & 4,10 & Baik \\
\hline
\end{tabular}

Peran penyuluhan dilihat dari edukasi menunjukkan bahwa penyuluhan sudah dalam kategori baik untuk persepsi peternak terhadap pemanfaatan limbah perusahaan peternakan yang diperlihatkan dengan skor 4, 09. Variabel edukasi tersebut diukur dari relevansi materi dengan kebutuhan dalam pemanfaatan limbah perusahaan peternakan, peningkatan pengetahuan, peningkatan keterampilan serta lama waktu bimbingan.

Peran penyuluhan dilihat dari diseminasi menunjukkan bahwa penyuluhan dalam kategori baik untuk kegiatan pemanfaatan limbah perusahaan peternakan yang diperlihatkan dengan skor 3,94. Variabel diseminasi diukur dari penyebaran informasi kepeternak lain yang tidak mengikuti penyuluhan, penyampaian 
informasi teknologi pemanfaatan limbah dan penyampaian informasi harga pupuk sebagai limbah peternakan.

Peran penyuluhan dilihat dari fasilitasi menunjukkan bahwa penyuluhan dalam kategori sangat baik untuk kegiatan pemanfaatan limbah perusahaan peternakan yang diperlihatkan dengan skor 4,23. Variabel fasilitasi tersebut diukur dari kemampuan memfasilitasi keluhan yang sudah dirasakan manfaatnya oleh peternak seperti fasilitasi permodalan,pengembangan minat berusaha yang sudah mampu memotivasi peternak, mewujudkan kemitraan peternak dengan pengusaha yang mampu membeli dengan harga pupuk yang lebih baik,akses ke lembaga keuangan yang mudah,akses pasar untuk hasil limbah peternakan yang dibantu oleh penyuluh dalam memasarkan sehingga harga bisa lebih baik.

Peran penyuluhan dilihat dari konsultasi menunjukkan bahwa penyuluhan dalam kategori baik untuk kegiatan pemanfaatan limbah yangdiperlihatkan dengan skor 4,03. Variabel konsultasi tersebut diukur dari kemampuan penyuluhan membantu memecahkan masalah peternak, memberikan sarana dan prasarana pemecahan masalah bersama dengan mendatangkan ahli pertanian dari tingkat kabupaten atau provinsi, pemahaman tentang teknologi terbaru dan waktu konsultasi secara rutin baik langsung ataupun tidak langsung.

Peran penyuluhan dilihat dari supervisi menunjukkan bahwa penyuluhan dalam kategori sangat baik untuk kegiatan pemanfaatan limbah peternakan yang diperlihatkan dengan skor 4,23. Variabel supervisi tersebut diukur dari pembinaan kemampuan teknis berusaha yang sudah mampu diwujudkan,pembinaan pemasaran hasil dengan mengajarkan pentingnya mencari pasar yang potensial dan tidak hanya fokus dengan pasar didesa tempat tinggal saja, sertapembinaan pemanfaatan sumber daya manusia sehingga mampu menghasilkan peternak yang menguasai teknologi untuk memanfaatkan sumber daya alam secara berkelanjutan.

Peran penyuluhan dilihat dari monitoring dan evaluasi menunjukkan bahwa penyuluhan dalam kategori baik untuk kegiatan pemanfaatan limbah perusahaan peternakan yang diperlihatkan dengan skor 4,12. Variabel monitoring dan evaluasi tersebut diukur dari kemampuan memonitoring terhadap usaha peternakan yang telah dijalankan dengan baik,melakukan monitoring dan evaluasi terhadap penguasaan inovasi/teknologi baru dalam pemanfaatan limbah dan teknologi beternak ayam ras, evaluasi hasil kegiatan output penyuluhan sehingga 
penyuluh mengetahui kegiatan apa yang perlu ditambahkan kedepan,evalausi kinerja peternak baik teknis ataupun finansial sehingga dapat diketahui rata-rata pendapatan peternak dari kegiatan penyuluhan (Yunasaf dan taspirin 2011).

\section{Penilaian Persepsi Peternak Terhadap}

\section{Pemanfaatan Limbah}

Penilaian persepsi peternak terhadap pemanfaatan limbah perusahaan peternakanberdasarkan Tebel 6menunjukan dalam ketegori sangat baik dengan skor 4,26. Variabel ini diukur berdasarkan indikator pemanfaatan limbah perusahaan peternakan menjadi pupuk kandang dengan skore 4,33, menjadi pakan 4,36 , biogas 4,10, pengelolaan limbah secara moderen 4,20 dan peningkatan ekonomi peternak 4,33. Hasil ini menunjukan bahwa peternak telah menerima adopsi inovasi yang diberikan oleh penyuluh melalui program penyuluhan sehingga pada kenyataanya peternak sudah mampu membuat sistem perkandangan diatas kolam ikan sebagai upaya untuk memanfaatkan kotoran ayam yang jatuh pada kolam, kemudian dijadikan pakan untuk ikanCatootjie et al., (2016).Pemanfaatan limbah perusahaan peternakan ini memiliki manfaat langsung maupun tidak langsung bagi peternak dan masyarakat disekitar lokasi perusahaan peternakan (Setiana, 2005). Hasil analisis diperoleh pendapatan peternak dalam perusahaan peternakan lebih tinggi, berdasarkan hasil tersebut maka pemanfaatan limbah perusahaan peternakan memiliki dampak ekonomi terhadap peningkatan pendapatan peternak dan penghematan pengeluaran energi masyarakat hal ini sesuai dengan pendapat Hartati et al., (2011) bahwa untuk tercapainya perubahan perilaku peternak demi terwujudnya perbaikan mutu hidup perlu disampaikan melalui kegiatan penyuluhan dan inovasi yaitu sesuatu yang dinilai baru atau dapat mendorong terjadinya pembaharuan.Peran penyuluhan dalam pemanfaatan limbah perusahaan peternakan sangat diperlukan agar peternak dapat meningkatkan keberdayaannya dan diharapkan dapat menciptakan inovasi-inovasi baru dalam usaha peternakan ayam ras. Rafiani et al., (2016) menjelaskan dalam penelitian nya bahwa keaktifan penyuluh dilapangan juga berpengaruh terhadap peternak agar peternak lebih aktif dan kreatif dalam menjalankan usahanya serta dapat menjalin hubungan yang lebih baik antara penyuluh dengan peternak ayam ras petelur. 
Tabel 6. Penilaian Persepsi Peternak Terhadap Pemanfaatan Limbah.

\begin{tabular}{lll}
\hline Variabel dan Indikator & Skore & Kategori \\
\hline Pemanfaatan limbah & 4,26 & Sangat baik \\
1. Menjadi pupuk & 4,33 & Sangat baik \\
2. Menjadi pakan & 4,36 & Sangat baik \\
3. Pemnafaatan Biogas & 4,10 & Baik \\
4. Penglolaahn limbah modern & 4,20 & Sangat baik \\
5. Peningkatan ekonomi & 4,33 & Sangat baik \\
\hline
\end{tabular}

\section{KESIMPULAN}

1. Peran penyuluhan dilihat dari edukasi, diseminasi, fasilitasi, konsultasi, supervisi dan monitoring/evaluasi yang ditunjukan dengan skore 4,10 dalam kategori baik pada pemanfaatan limbah perusahaan peternakan ayam ras di Desa Tateli Kecamatan Mandolang Kabupaten Minahasa.

2. Peternak mampu memanfaatkan limbah perusahaan peternakanmenjadi pupuk dan pakan ikan sehinggah meningkatkan nilai ekonomi dan menanggulangi dampak lingkungan.

\section{DAFTAR PUSTAKA}

Adjid, D.A. 2001. Membangun Pertanian Modern. Yayasan Pengembangan Sinar Tani. Jakarta.

Amanah, S. 2007. Makna Penyuluhan dan Transformasi Perilaku Manusia. Jurnal Penyuluhan. 3 (1):64-66.

Catootjie, L., Nalle dan M.R.K. Yowi. 2016. Penerapan Teknologi Pakan Ternak dan Pengolahan Limbah Peternakan di Desa Oeltua Kab. Kupang. Jurnal Pengabdian Masyarakat Peternakan.1 (1):40-46.

Hartati, P., M.Y. Surung., A. Wahab. 2011. Analisis Kinerja Penyuluh Pertanian di Kabupaten Bantaeng Sulawesi Selatan. Jurnal Agrisistem.7 (2):95-97.
Mardikanto. 2009. Sistem Penyuluhan Pertanian. Sebelas Maret University Press.Surakarta.

Rafiani, I.R., Muksin dan Rizal. 2016. Peran dan Kinerja Penyuluh Pertanian dalam Memberdayakan Peternak Ayam Petelur di Kabupaten Jember Provinsi Jawa Barat. Jurnal Penyuluhan. 12 (2):183-189.

Risna., M. Rosni dan Mariani. 2012. Peran Penyuluhan Pertanian Terhadap Pengendalian Hama Terpadu pada Tanaman Padi Berdasarkan Kelas Kemampuan Kelompok Tani di Kecamatan Labuan Amas Selatan Kabupaten Hulu Sungai Tengah. Jurnal Agribisnis Perdesaan. 2 (3): 215-219.

Setiana, L. 2005. Teknik Penyuluhan dan pemberdayaan Masyarakat.Penerbit Graha Indonesia.Ciawi. Bogor.

Sugiyono. 2012. Metode Penelitian Kuantitatif Kualitatif dan R\&D. Bandung: Alfabeta.

Yunasa f,U dan D.S. Tasripin. 2011. Peran Penyuluh dalam Proses Pembelajaran Peternak Sapi Perah di KSU Tandangsari Sumedang. Jurnal Ilmu Ternak.11(2):99-102. 